Special Issue on Migration and Globalization, Canadian Studies in Population

Vol. 29(1), 2002, pp. 151-171

\title{
Refugees into Immigrants: \\ Assessing the Adjustment of Southeast Asian Refugees \\ in the U. S., 1975-1990
}

\section{K. Bruce Newbold}

School of Geography and Geology

McMaster University

Hamilton, Ontario

\begin{abstract}
Embodying a differential set of skills, refugees experience varying obstacles and reception upon entry into their host country. Starting in 1975, the U.S. received large numbers of refugees from Southeast Asia. Although these arrivals are no longer labeled as 'refugees', their initial immigration status raises interesting questions, including whether or not they match the attainment of those who arrived in the U.S. at the same time. Using the 1980 and 1990 Public Use Microdata Files (PUMS), this paper traces the adaptation of post-1975 Southeast Asians within the U.S. through the lens of segmented assimilation. Refugee flows are disaggregated into Sino-Vietnamese, Ethnic-Vietnamese, Hmong, Cambodians, and Laotian identities and contrasted to Chinese immigrants.
\end{abstract}

Key Words: Refugees, immigrants, United States 


\section{Résumé:}

Embodying a differential set of skills, refugees experience varying obstacles and reception upon entry into their host country. Starting in 1975, the U.S. received large numbers of refugees from Southeast Asia. Although these arrivals are no longer labeled as 'refugees', their initial immigration status raises interesting questions, including whether or not they match the attainment of those who arrived in the U.S. at the same time. Using the 1980 and 1990 Public Use Microdata Files (PUMS), this paper traces the adaptation of post-1975 Southeast Asians within the U.S. through the lens of segmented assimilation. Refugee flows are disaggregated into Sino-Vietnamese, Ethnic-Vietnamese, Hmong, Cambodians, and Laotian identities and contrasted to Chinese immigrants.

Key Words: Refugees, immigrants, United States

\section{Introduction}

Over the past two decades, approximately 10 to 15 percent of immigrant inflows to the U.S. have been refugees, with origins such as Cuba, Southeast Asia, and Eastern Europe reflecting both federal refugee policies and the generators of refugee flows (Zlotnik 1996). On the assumption that a dispersed settlementpattern would speed their social and economic adaptation to American society, private and public programs, such as the Cuban RefugeeRelocation Program or the Inter Agency Task Force on Refugees, have often guided their settlement within the U.S. (Baker and North 1985; Bean and Tienda 1987; Desbarats 1985; 1986; McHugh et al 1997).

Among refugee groups that have received considerable attention within the literature are the Southeast Asian refugees, which include Vietnamese, Cambodians and Laotians (see, for example, Baker and North 1985; Desbarats 1985, 1986; Haines 1989; Portes and Rumbaut 1996). Out of these three groups, the Vietnamese represented the majority of arrivals, with Laotians and Cambodians accounting for smaller but significant shares. Despite their comparable lengths of residency within the U.S., the Southeast Asian population is a highly diverse one. Ethnically, the group is divisible into a minimum of five ethnic groups, including Sino-Vietnamese, ethnic-Vietnamese, Hmong, Cambodians, and Laotians. These groups also differ with respect to arrival and settlement histories. Precipitated by the fall of Saigon in April 1975, the initial wave of Vietnamese refugees reflected 
Refugees into Immigrants: Assessing the Adjustment of Southeast Asian Refugees in the U.S., 1975-1990

the relative 'elite' of the country, with somewhat higher levels of education and greater English language abilities than those who arrived earlier (Haines 1989). Followed by a lull of two or three years, the number of refugees from Southeast Asian countries rose again in response to political conditions, oppression, and genocide by leaders within the respective countries. Responding to this mounting crisis, the U.S. government doubled entry quotas to 14,000 per month in 1980 . This second wave of refugee arrivals was more ethnically heterogeneous, including ethnic-Vietnamese and Sino-Vietnamese 'boat people', survivors of the Pol Pot regime in Kampuchea, the lowland Lao, and the Hmong (Desbarats 1985; Haines 1989). Second wave arrivals had generally lower levels of endowed human capital, with many coming from rural areas with little education, poor knowledge of the English language, and few labour skills (Haines 1989; Desbarats 1986). Following 1982, admission levels were reduced, although the Immigration and Naturalization Service (INS) recorded the entry of some 15,000 Vietnamese refugees even in fiscal year 1990, or approximately 39 percent of all arrivals from Vietnam. The Vietnamese were eligible to apply for refugee status until 1994 (Isbister 1996; INS 1995).

Post-1980 arrivals faced additional hardships. Cambodian and Laotian refugees arriving after 1980 were part of an arrival cohort that was bigger than all previous arrival cohorts, entering the country during a national recession in the early 1980 s and at a time of increasing 'compassion fatigue' within the lay public (Haines 1989), making for a less favourable reception. Vietnamese arrivals faced (for better or worse) an establishedrefugee community, albeit one that was only five years old (Gordon 1989). While the existing Vietnamese community may provide linkages to employment, housing, or an opportunity to live and work with co-nationals, it may also slow adaptation by insulating new arrivals from the broader social and economic environment. Differences in ethnicity and endowed human capital also distinguish pre- and post-1980 arrivals, with post-1980 arrivals tending to have lower levels of labour force participation, higher joblessness rates, and less rapid increases in labour market involvement, indicating a decreased ability to find work among the less skilled (Portes and Rumbaut 1996).

Although most refugees went on to adjust their legal status, becoming permanent residents or naturalized citizens (Portes and Rumbaut 1996), considerable betweengroup differences remained even after residing within the U.S. for some time. Although the impact of the Federal government's attempt at dispersion was still visible, the Vietnamese were characterized by increasingspatial concentrationat the state and local levels. Prior to 1975, no sizeable Vietnamese community existed within the U.S., but approximately 45 percent of the Indochinese refugees who arrived in the U.S. in 1975 resided in a different state by 1980, with secondary migration occurring shortly after arrival (Baker and North 1984; Desbarats 1986). Later, the emergence of ethnic communities within metropolitan areas such as Los Angeles reinforced the in-migration of co-ethnics while attracting new refugee arrivals. Since then, the Vietnamese have become increasingly concentrated in metropolitan areas including San Francisco, Los Angeles and Washington D.C., with preferred settlement locations including urban areas, areas with milder climates, and areas for which refugees had prior information. An emerging Vietnamese business class contrasts with other Southeast Asian refugees, best 
reflected by the Laotian population, who continue to have lower rates of business ownership and are more likely to be dependent upon public assistance programs and on manual wage labour (Portes and Rumbaut 1996). Laotians have also remained more dispersed.

While it is generally believed that the Indochinese have successfully settled and adapted within the U.S., their success relative to each other as well as later arrivals may vary. Set within Portes' segmented assimilation framework and drawing upon 1980 and 1990 census data, this paper traces the evolution of post-1975 Southeast Asian refugees within the U.S., comparing settlement patterns and other measures of social, economic and cultural adaptation. In particular, it follows selected refugee cohorts through the lens of segmented assimilation, a framework that offers one way of accounting for between group differences.

\section{Refugees and Assimilation: Theoretical and Empirical Issues}

Early work in the fist half of the twentieth century by American sociologists viewed assimilation as the end result of a linear process that turned immigrants into Americans, and as a process that all would pass through (Park 1928). With the increasing realization that a uniform process of assimilation was implausible, scholars advanced alternate theories. Gordon (1964), for example, argued that assimilation into the host society was, in fact, a multidimensional process represented by cultural (acculturation), and defining different paths of learning the language and culture of a society. Assimilation could also be evaluated with respect to social, economic, and spatial indicators (see also discussions by Allen and Turner (1996); Aycan and Berry (1996), Chataway and Berry (1989), and Isajiw (1999)). Moreover, changes in one aspect (i.e., social) were not necessarily reflected in concomitant changes in other aspects (i.e., economic or spatial). Despite the fact that acculturation was defined as the first step in an adaptation process that ultimately lead to assimilation (Portes and Rumbaut 1996), the process had no coherent structure specifying how these various dimensions were related to the final outcome (Hirschman 2001). In addition, reforms to immigration law in 1965, which changed origin countries and removed racial and ethnic barriers to immigration, strained the assimilation model beyond its abilities. Recent literature has, consequently, questioned the assumption of uniform assimilation, with contemporary scholars arguing that assimilation does not necessarily or automatically lead to similarity and equality with mainstream culture (Massey 1985).

As a variation on a theme, Portes' segmented assimilation theory $(1994,1995)$ represents a re-thinking of the traditional assimilationist model, providing a more complex accounting of how and why immigrants follow different paths of incorporation into society. Within this framework, assimilation hinges upon the endowed human capital (i.e., labour force skills, savings, education) of entrants, the public and private reception of new arrivals (which frequently parallels government policy and economic opportunities), and the 'nature' of immigration (voluntary or forced). Consequently, assimilation does not necessarily or 
Refugees into Immigrants: Assessing the Adjustment of Southeast Asian Refugees in the U.S., 1975-1990

automatically lead to similarity and equality with mainstream culture, nor is this the only outcome. Instead, a diversity of outcomes within and between immigrant groups is possible, with some groups quickly realizing integration into the mainstream society, and others not (Portes 1994; Portes and Borocz 1989; Portes and Zhou 1994).

While the segmented assimilation framework provides a lens through which to observe and understand the differing modes of immigrant adaptation, it is one of a number of competing hypotheses and thus waits to be confirmed. Moreover, it is debatable whether or not the framework can be applied to the refugee population, given the enormous differences between voluntary and involuntary departure of immigrants and refugees and the social and economic makeup of the groups themselves. Often embodying a differential set of skills and personal attributes, the experiences and benchmarks of immigrants and refugees will likely differ. On the one hand, legal immigrants are typically positively selective, searching for better opportunities. Immigrants are frequently able to draw directly upon family support mechanisms to ease adjustment in the new community and provide linkages to employment or housing while interacting within a culturally similar environment. In contrast, refugees and asylees are often the least successful of all foreign arrivals, with their selection frequently reflecting the foreign policy agenda of the U.S. over the past three decades.

Forced to flee their homeland to avoid religious, economic, political or cultural persecution, their journey commonly ends in a destination simply by accident of government policy or the intervention of sponsor agencies and groups. Their assigned destination may further isolate them from co-nationals, even when the very aim of such policies is to aid their social and economicadaptation to America. In contrast to other legal immigrants, refugees often lack the necessary networks within the host community to assist in the location of housing or employment opportunities. More likely to require assistance from local or state agencies or social groups, refugees impose greater fiscal burdens on local and federal governments (Clark 1998; Isbister 1996). Although not guaranteeing adaptation to the host country, the provision of financial assistance represents an important component of the early experiences of refugees absent among other immigrants. The inability to return home also engenders differences relative to other immigrants, affecting attitudes toward America and their adaptation (Portes and Borocz 1989). Like their legal immigrant counterparts, the public and private reception of refugees will vary. Hungarians and Czechs, who escaped invasions of their countries, have managed to avoid the prejudice and discrimination typically focused upon other immigrant groups, enabling a more favorable reception and relative success within America (Portes and Zhou 1994). Race also plays a role in their adjustment: in addition to fleeing regimes that the U.S. government did not support, they were white, while refugees from elsewhere, including 'black' Cubans have faced barriers of racism and discrimination, even as the larger Cuban population has succeeded (Skop 2001). Similarly, Desbarats (1986) noted differences in the adaptation of Sino- and ethnic Vietnamese refugees in the U.S.

Yet, the refugee label is also a transitory one, with many refugees becoming legal, permanent residents or naturalized citizens, raising questions relating to their 


\section{K. Bruce Newbold}

adaptation. Is, for example, the adaptation process of a refugees group similar or different to other refugee groups or immigrants? In other words, is there evidence that the assimilation process of refugees is segmented, with refugee groups attaining similar (different) benchmarks or levels of adjustment in the U.S. relative to each other or the broader immigrant population? Differences across refugee groups in terms of human capital, timing of arrival, and reception will most likely lead to differential paths of assimilation within the U.S.. While such differences in the adaptation of refugee groups to America may be expected, the assumption has not been rigorously tested. By using the 1980 and 1990 Public Use Microdata Sample (PUMS) of the U.S. Census and carefully defining refugee arrival groups, the following traces the evolution of post-1975 Southeast Asian refugees within the U.S., comparing settlement patterns and other measures of social, economic and cultural adaptation through the lens of the segmented assimilation framework.

\section{Data and Methods}

Utilizing the 1980 and 19905 percent PUMS (U.S. Bureau of the Census 1983, 1992), the Southeast Asian population was selected for analysis. If, however, the adjustment of the refugee population is of interest, three empirical issues must be addressed. First, how can the refugee population be identified within public samples such as the Census that do not identify the type of immigrant? Census files do not include informationpertaining to admission category, capturinginstead 'all' immigrants, including short-term residents, legal immigrants, illegal aliens, and refugees within the foreign-born category. This has meant that the immigrant population is treated as an aggregate, even though important differences are likely to be observed across admission categories, impacting upon measures of assimilation. Yet, it is also known that particular countries generate a large proportion of refugee flows. Reflective of Cold war and anti-Communist agendas within the U.S. government and various administrations, refugee policy has typically been viewed as a foreign-policy tool (Zlotnik 1996). Not surprisingly, countries such as Cuba, Afghanistan, Romania, Czechoslovakia, Cambodia, and Laos generated large numbers of refugees in the 1980s. Between 1975 and 1979, refugees from Vietnam numbered approximately 255,000 (Desbarats 1985), with an additional 300,000 arrivals between 1980 and 1990. Put another way, approximately 80 percent of entrants from Vietnam between 1980-90 were refugees, with this proportion approaching 100 percent at the height of the Southeast Asian refugee crisis in late 1970s and early 1980s. Similarly, nearly 100 percent of entrants from Cambodia and Laos during the late 1970s and early 1980s were classified as refugees (INS 1995).

Knowing which origins produce large numbers of refugees allows their identification within the PUMS and permits the consideration of a variety of factors, including migration, measures of human capital, and other personal effects (Newbold 2000). Identifying refugee origins within the PUMS requires the assumption that all foreign-born arrivals during a particular period from Vietnam, Cambodia and Laos were refugees. While clearly a reasonable assumption for these countries during the period in question (1975-84), since greater than 90 percent of 
Refugees into Immigrants: Assessing the Adjustment of Southeast Asian Refugees in the U.S., 1975-1990

all entrants in the late 1970s and early 1980s were refugees, it would be more problematic in situations where the proportion of refugees is smaller, clouding the analysis of immigrant - refugee differences. Importantly, the intent is not to completely replicate the refugee population, but to identify origins producing large numbers of refugees within the immigrant flow, relate them to census data, and to compare refugees with immigrants. This allows consideration of questions such as whether or not refugees demonstrate dissimilar population distributions, mobility rates, or personal attributes.

Second, the adaptation of refugees arriving at different times periods cannot be directly compared relative to that of later arrivals owing to 'compositional' effects embedded within each arrival cohort (Meyers and Lee 1996). Capturing issues such as period of arrival, shifting immigration policies, cohort size, or the human capital of arrivals, compositional effects imply that arrival cohorts are not directly comparable. The failure to adopt an adequate temporal framework suitable for the analysis of immigrant population systems may quickly lead to misconceptions associated with immigration and adaptation (Myers and Lee 1996). For instance, the ability of some of the earliest Vietnamese arrivals to adjust to U.S. society cannot be directly compared with later arrivals, which have experiencedlower levels of labour force participation, higher joblessness rates, and less rapid increases in labour market involvement (Portes and Rumbaut 1996). Rather, have the experiences of refugees matched the benchmarks and attainment of other groups arriving at the same time?

Third, given the lack of true, longitudinal data and the need to define an appropriate temporal framework, consecutive census files are linked, with data derived from the 1980 and 1990 PUMS (U.S. Bureau of the Census, 1983, 1992). Since the on-going arrival of new immigrants restructures the settlement system, the analysis focuses upon changes and differentials in migration and settlement by cohort (Borjas, 1985; Borjas and Bratsberg 1996).

In order to control for these problems, the 'double cohort' method is used (Myers and Lee 1996), defining the immigrant population by age and time of arrival, therefore allowing intergenerational and arrival effects to be controlled, focusing upon Vietnamese, Cambodian, and Laotian refugees arriving between 1975 and 1984. Refugee origins are further disaggregated by ethnicity to reveal five groups, including Sino-Vietnamese, ethnic-Vietnamese, Hmong, Lao, and Cambodians. Cambodian responses include Khmer, and Lao responses include Laotiansand Meo groups, neither of which could be further subdivided within the PUMS. Chinese arrivals during the same period are included in the analysis for comparative purposes, since the majority of Chinese entrants were legal immigrants (INS 1995). Two arrival groups are defined for each of these six groups, including;

Arrivals between 1975 and 1979 who were aged 20-54 at the time of entry; Arrivals between 1980 and 1984 who were aged 25-59 at the time of entry;

Cohorts were then allowed to 'age' so that the cohorts of 1975-79 and 1980-84 arrivals were both aged 30-64 by 1990, thus allowing changes in effects such as location, concentration, or personal attributes to be traced and compared over time. 
While individuals cannot be followed across census intervals, changes in aggregate group behaviour can be evaluated.

Subsequent analysis focuses upon (i) the proportional distribution of the refugee population at the state and metropolitan scale, and (ii) measures of acculturation and assimilation that have been widely used in the past and capture the diversity of the process (see, for example, Allen and Turner 1996; Goldman 1998; Portes 1995; Portes and Rumbaut 1996). No a priori expectations are assigned to these relationships, as effects may vary within and between cohorts and refugee groups. Being one of the first stages of assimilation in which refugees integrate themselves into society, cultural assimilation is reflected by English language ability (percent who speak the English 'well' or 'excellent') and naturalization (percent with U.S. citizenship). Although citizenship is not necessary as a part of assimilation, it may be viewed as an indicator of commitment and permanency within the U.S.. Education level, measured as the percent having less than a high school education, represents an additional indicator of acculturation (Allen and Turner 1996). Economic assimilation can be measured by poverty status (percent below the poverty level), class of worker (percent self-employed), and occupation (percent in professional occupations).

\section{Results}

\section{Geographical Distribution: Settlement and Resettlement}

The government, along with private groups, often decides the resettlement locations of refugees. Resettlement of Southeast Asian refugees occurred under the auspices of the Inter Agency Task Force on Indochinese Refugees, with the intended goal being to disperse the population, thereby facilitatingtheir adjustment to American society while reducing the perceived economic burdens they may represent to the receiving area. This potential for redistribution of refugee groups can be observed through the more 'traditional' portrait of settlement patterns emerging from census files. Linkage of the 1980 and 1990 PUMS files allows the South Asian refugee groups to be identified at three points in time (1980, 1985 and 1990). Their decision to relocate most likely expresses their 'preferred' destination (Portes and Rumbaut 1996) or their 'established' settlement location (Newbold 1999), meaning the settlement system that evolves over time. Although having comparable lengths of residency within the U.S., the six groups differ in their concentration and, by extension, their propensity to relocate.

Tables 1 and 2 report the proportional share of refugees for the top three destinations by period of arrival. While the preference among the Chinese for destinations in New York or California is visible, the observed distribution among refugees is more diffuse and less stable, reflecting the outcome of policies aimed at dispersion and post-arrival migration. Of the five groups, ethnic and SinoVietnamese share the most similar settlement patterns, with Los Angeles home to a large and increasing proportion of both 1975-79 and 1980-84 arrivals, and San Francisco the second most important destination for both groups. The New York 
Table 1

Observed Destination of 1975-79 Arrivals: 1980, 1985, and 1990

\begin{tabular}{|c|c|c|c|c|c|c|}
\hline \multirow{2}{*}{$\begin{array}{c}\text { State and } \\
\text { Metropolitan Area }\end{array}$} & \multicolumn{2}{|l|}{ First } & \multicolumn{2}{|c|}{ Second } & \multicolumn{2}{|c|}{ Third } \\
\hline & Destination & $(\%)$ & Destination & $(\%)$ & Destination & $(\%)$ \\
\hline \multicolumn{7}{|l|}{ A) State } \\
\hline \multicolumn{7}{|l|}{1980} \\
\hline Sino-Vietnamese & California & 42.4 & New York & 7.0 & Texas & 6.3 \\
\hline Eth.-Vietnamese & California & 37.7 & Texas & 9.0 & Virginia & 4.7 \\
\hline Cambodian & California & 31.9 & Texas & 9.5 & Rhode Island & 9.5 \\
\hline Laotian & California & 25.9 & Illinois & 8.1 & Washington & 6.1 \\
\hline Hmong & Minnesota & 25.4 & California & 23.4 & Utah & 13.4 \\
\hline Chinese & California & 38.7 & New York & 18.9 & Texas & 5.2 \\
\hline \multicolumn{7}{|l|}{1985} \\
\hline Sino-Vietnamese & California & 58.7 & Texas & 6.4 & New York & 5.1 \\
\hline Eth.-Vietnamese & California & 40.9 & Texas & 14.2 & Louisiana & 4.1 \\
\hline Cambodian & California & 46.7 & Texas & 8.2 & Pennsylvania & 7.6 \\
\hline Laotian & California & 30.3 & Texas & 11.3 & Illinois & 6.0 \\
\hline Hmong & California & 45.2 & Wisconsin & 16.1 & Minnesota & 14.5 \\
\hline Chinese & California & 35.5 & New York & 21.9 & Texas & 8.8 \\
\hline \multicolumn{7}{|l|}{1990} \\
\hline Sino-Vietnamese & California & 60.4 & Texas & 5.7 & New York & 5.0 \\
\hline Eth.-Vietnamese & California & 43.3 & Texas & 14.8 & Virginia & 4.1 \\
\hline Cambodian & California & 47.9 & Texas & 9.0 & Pennsylvania & 7.6 \\
\hline Laotian & California & 31.3 & Texas & 12.0 & Minnesota & 4.8 \\
\hline Hmong & California & 50.0 & Wisconsin & 16.0 & Minnesota & 15.1 \\
\hline Chinese & California & 36.2 & New York & 19.9 & Texas & 9.3 \\
\hline \multicolumn{7}{|l|}{ B) Metro } \\
\hline \multicolumn{7}{|l|}{1980} \\
\hline Sino-Vietnamese & Los Angeles & 21.8 & San Francisco & 13.1 & New York & 7.5 \\
\hline Eth.-Vietnamese & Los Angeles & 21.3 & San Francisco & 10.8 & Houston & 5.0 \\
\hline Cambodian & Los Angeles & 15.5 & Minneapolis & 8.6 & San Francisco & 6.9 \\
\hline Laotian & Los Angeles & 12.5 & Chicago & 5.5 & San Diego & 5.2 \\
\hline Hmong & Minneapolis & 19.4 & Los Angeles & 13.4 & Portland & 10.5 \\
\hline Chinese & New York & 19.9 & Los Angeles & 19.3 & San Francisco & 15.6 \\
\hline \multicolumn{7}{|l|}{1985} \\
\hline Sino-Vietnamese & Los Angeles & 32.2 & San Francisco & 7.7 & New York & 4.7 \\
\hline Eth.-Vietnamese & Los Angeles & 25.6 & San Francisco & 5.5 & Houston & 5.0 \\
\hline Cambodian & Los Angeles & 31.2 & Philadelphia & 5.6 & Portland & 5.0 \\
\hline Laotian & Los Angeles & 9.9 & Dallas & 4.9 & Fresno & 4.6 \\
\hline Hmong & Fresno & 17.8 & Minneapolis & 14.0 & Los Angeles & 3.2 \\
\hline Chinese & New York & 23.1 & Los Angeles & 15.3 & San Francisco & 11.8 \\
\hline \multicolumn{7}{|l|}{1990} \\
\hline Sino-Vietnamese & Los Angeles & 34.6 & San Francisco & 20.4 & New York & 5.2 \\
\hline Eth.-Vietnamese & Los Angeles & 25.3 & San Francisco & 12.6 & Houston & 8.5 \\
\hline Cambodian & Los Angeles & 30.9 & San Francisco & 9.3 & Portland & 5.6 \\
\hline Laotian & Los Angeles & 9.0 & San Francisco & 4.7 & San Francisco & 4.7 \\
\hline Hmong & Fresno & 21.4 & Minneapolis & 15.0 & Stockton & 6.2 \\
\hline Chinese & New York & 22.6 & San Francisco & 18.0 & Los Angeles & 15.8 \\
\hline
\end{tabular}

Source: 1980, 1990 PUMS, author's tabulations. 
Table 2

Observed Destination of 1980-84 Arrivals: 1985 -1990

\begin{tabular}{|c|c|c|c|c|c|c|}
\hline \multirow{2}{*}{$\begin{array}{c}\text { State and } \\
\text { Metropolitan Area }\end{array}$} & \multicolumn{2}{|l|}{ First } & \multicolumn{2}{|c|}{ Second } & \multicolumn{2}{|l|}{ Third } \\
\hline & Destination & $(\%)$ & Destination & $(\%)$ & Destination & $(\%)$ \\
\hline \multicolumn{7}{|l|}{ A) State } \\
\hline 1985 & & & & & & \\
\hline Sino-Vietnamese & California & 63.9 & Texas & 5.2 & New York & 5.1 \\
\hline Eth.-Vietnamese & California & 48.3 & Texas & 9.7 & Virginia & 3.8 \\
\hline Cambodian & California & 38.6 & Texas & 7.5 & Massachusetts & 7.3 \\
\hline Laotian & California & 37.4 & Washington & 5.7 & Texas & 5.6 \\
\hline Hmong & California & 59.3 & Minnesota & 18.8 & Wisconsin & 12.0 \\
\hline Chinese & California & 34.7 & New York & 26.4 & Texas & 8.2 \\
\hline \multicolumn{7}{|l|}{1990} \\
\hline Sino-Vietnamese & California & 65.5 & Texas & 5.8 & New York & 4.8 \\
\hline Eth.-Vietnamese & California & 52.0 & Texas & 9.5 & Virginia & 3.9 \\
\hline Cambodian & California & 43.8 & Massachusetts & 9.2 & Washington & 6.7 \\
\hline Laotian & California & 40.6 & Texas & 5.5 & Illinois & 5.4 \\
\hline Hmong & California & 61.5 & Minnesota & 22.5 & Wisconsin & 10.7 \\
\hline Chinese & California & 35.5 & New York & 25.2 & Texas & 8.1 \\
\hline \multicolumn{7}{|l|}{ B) Metro } \\
\hline 1985 & & & & & & \\
\hline Sino-Vietnamese & Los Angeles & 33.0 & San Francisco & 8.4 & New York & 5.7 \\
\hline Eth.-Vietnamese & Los Angeles & 24.5 & San Francisco & 6.1 & Washington & 3.3 \\
\hline Cambodian & Los Angeles & 20.7 & San Francisco & 5.4 & Boston & 5.0 \\
\hline Laotian & San Francisco & 5.2 & Los Angeles & 5.2 & Fresno & 4.3 \\
\hline Hmong & Fresno & 23.5 & Minnesota & 16.6 & Los Angeles & 4.3 \\
\hline Chinese & New York & 26.2 & Los Angeles & 13.6 & San Francisco & 8.8 \\
\hline \multicolumn{7}{|l|}{1990} \\
\hline Sino-Vietnamese & Los Angeles & 34.3 & San Francisco & 22.2 & New York & 5.8 \\
\hline Eth.-Vietnamese & Los Angeles & 26.8 & San Francisco & 16.6 & Houston & 4.7 \\
\hline Cambodian & Los Angeles & 24.6 & San Francisco & 8.4 & Boston & 7.0 \\
\hline Laotian & San Francisco & 9.1 & Sacramento & 5.8 & San Diego & 5.6 \\
\hline Hmong & Fresno & 25.8 & Minneapolis & 21.3 & Sacramento & 8.6 \\
\hline Chinese & New York & 26.5 & San Francisco & 18.3 & Los Angeles & 14.3 \\
\hline
\end{tabular}

Source: 1980, 1990 PUMS, author's tabulations. 
Refugees into Immigrants: Assessing the Adjustment of Southeast Asian Refugees in the U.S., 1975-1990

CMSA was the third most important home for Sino-Vietnamese, although its proportional share of 1975-79 arrivals decreased between 1980 and 1990, while ethnic Vietnamese preferred Houston as their third destination. Los Angeles was also home to the largest proportion of Cambodian and Laotian refugees. Second and third preferences between these two groups were more diverse, including Minneapolis-St. Paul, Dallas-Ft. Worth, Philadelphia, San Francisco, Portland, Chicago, San Diego, and Fresno metropolitan areas.

The success of programs aimed at dispersion appears to be relatively short lived, witnessed by the increasing concentration of the refugee groups in a few locations. While the emerging settlement system of most Southeast Asian refugee groups had a western bias, Minneapolis-St. Paul quickly emerged as an important center for the Hmong. Among 1975-79 arrivals, it was home to over 19 percent of the Hmong population in 1980, most of whom had arrived in the previous five years. Although few Hmong were resettled in Fresno when they first arrived in the U.S. (Portes and Rumbaut 1996), it also emerged as an important center, with over 21 percent of 1975-79 Hmong arrivals by 1990, eclipsing Minneapolis as the largest Hmong center. Fresno'simportance was further reinforced by Hmong arrivalsin the early 1980s, capturing approximately 25 percent of this group. After Fresno, Minneapolis and Los Angeles were the second and third most important destinations for the Hmong, respectively. Similar to the increasing concentration of the Vietnamese or Cambodians in Los Angeles, the evidence suggests the importance of post-arrival relocation and their increasing concentration in other cities, primarily in California.

The evolving concentration of the Hmong in Fresno and Minneapolis raises an interesting issue. Often times, the share of immigrant and refugee groups in the major metropolitan or state gateways is used as an indicator of their spatial concentration, largely since areas such as New York, California, Illinois or Texas reflect historical and contemporary settlement patterns (Frey 1996; Portes and Rumbaut 1996). The danger inherent in focusing upon this measure is revealed in Table 3, which notes the concentration in 1990 of these groups in the ten major state or metropolitan gateways. These settlement processes have led to two apparently contradictory outcomes among refugees: concentration in a few states and metropolitan areas, and diffusion from traditional gateways owing to significant variations in their locational decisions.

Despite initial dispersion across the U.S, important gateway areas including New York, Florida, or the New York and Miami metropolitan areas were home to relatively small proportions of Southeast Asian refugees, reflecting the bias toward western states and metropolitan areas. With over 75 percent of the 1975-79 arrival cohort living in the top ten metropolitan or state destinations, the Chinese were more concentrated than most refugee groups, a finding which is not surprising given their long history of settlement within the U.S.. The Sino- and EthnicVietnamese and Cambodians became increasingly concentrated in the major gateway state and metropolitan areas between 1980 and 1990. The SinoVietnamese were the most concentrated of the five refugee groups, with over 75 percent of 1975-79 arrivals located in these areas by 1990. Among 1975-79 arrivals, Sino-Vietnamese representation in the major metropolitan areas increased 


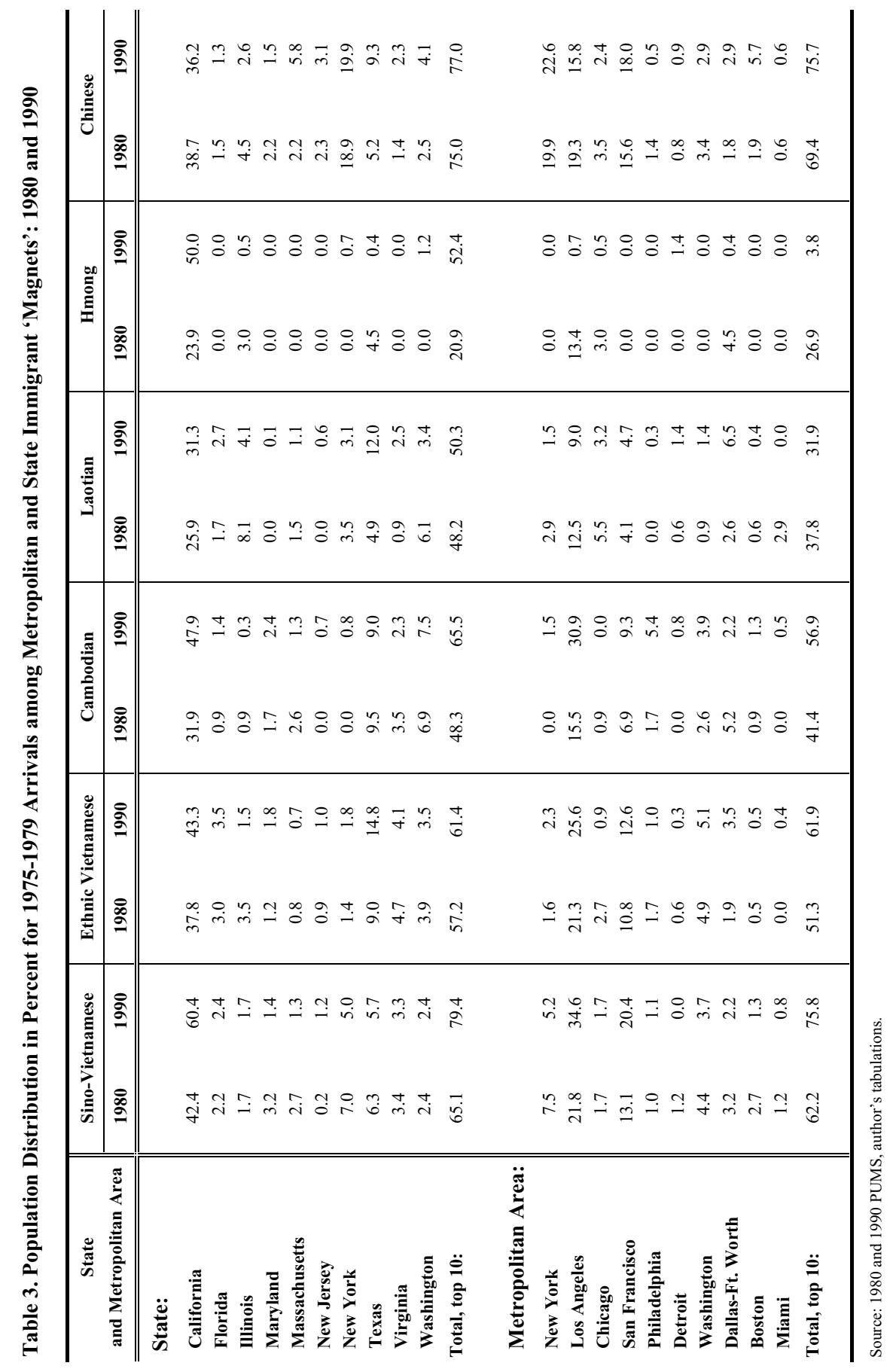


Refugees into Immigrants: Assessing the Adjustment of Southeast Asian Refugees in the U.S., 1975-1990

from 62.2 percent in 1980 to 75.8 percent in 1990. The second most concentrated were the ethnic-Vietnamese, with just over 60 percent in the major gateways. Similarly, Ethnic Vietnamese and Cambodians became increasingly concentrated in the major state and metropolitan gateways, albeit at lower levels.

Conversely, Laotians and Hmong appeared to 'disperse' from the major metropolitan areas during the same period. The Hmong, for example, are the most spatially 'dispersed' when measured relative to the major gateways, with less than 4 percent of 1975-79 arrivals in the major metropolitan gateways, and approximately 50 percent in the major state gateways. However, while these refugee groups tend to be less concentrated in the major gateway regions as compared to other refugees and legal immigrants (Newbold 2000; Portes and Rumbaut 1996), this does not mean that they are any less concentrated in specific areas. Instead, they are concentrated in centers that are not necessarily or immediately associated with large foreign-born populations, including the Minneapolis, Fresno and Stockton metropolitan areas as noted earlier.

\section{Changing Personal Attributes}

While legal immigrants are able to self-select into the immigration decision, refugees are unlikely to face such options, and instead face only hardships: forced to flee their homeland, the refugee population is more likely to reflect a broader diversity with respect to personal attributes relative to the legal immigrant population (Newbold 2000). The profile of each group depends, in part, on the evolution of the inflow, with initial waves of refugees tending to come from higher socioeconomic status groups. As the movement continues, refugees are increasingly drawn from lower status groups, a process that tends to be exacerbated when refugees originate in countries where upper status groups are a small proportion of the total population (Portes and Rumbaut 1996). Likewise, the receiving country will shape success and adaptation after arrival.

There is, in fact, a great diversity between Southeast Asian origins with respect to personal attributes, echoing their backgroundsalong with the success, opportunities and barriers to adjustment within the U.S. encounteredby these groups. Variations in the level of education highlight the heterogeneity among arrivals (see Table 4). With approximately 80 percent of 1975-79 arrivals having less than a high school education in 1990, the Hmong and Laotians are the least educated, even after some fifteen years in the country. Ethnic Vietnamese, on the other hand, are the most educated, with 54 percent having a high school (or better) education. Differences in the inflow of refugees helps to explain the variation between cohorts, with the more recent arrivals (1980-84) having levels of education that are comparable or worse than earlier arrivals.

Occupation and entrepreneurship are two additional ways to view the heterogeneity of the Southeast Asian refugee population. Despite attempts at integration, refugees continue to experience high unemployment and non-participation in the labour force. More recent arrivals (post-1980) face increased hardships, having lower participation rates, higher rates of joblessness, and a less rapid increase in 


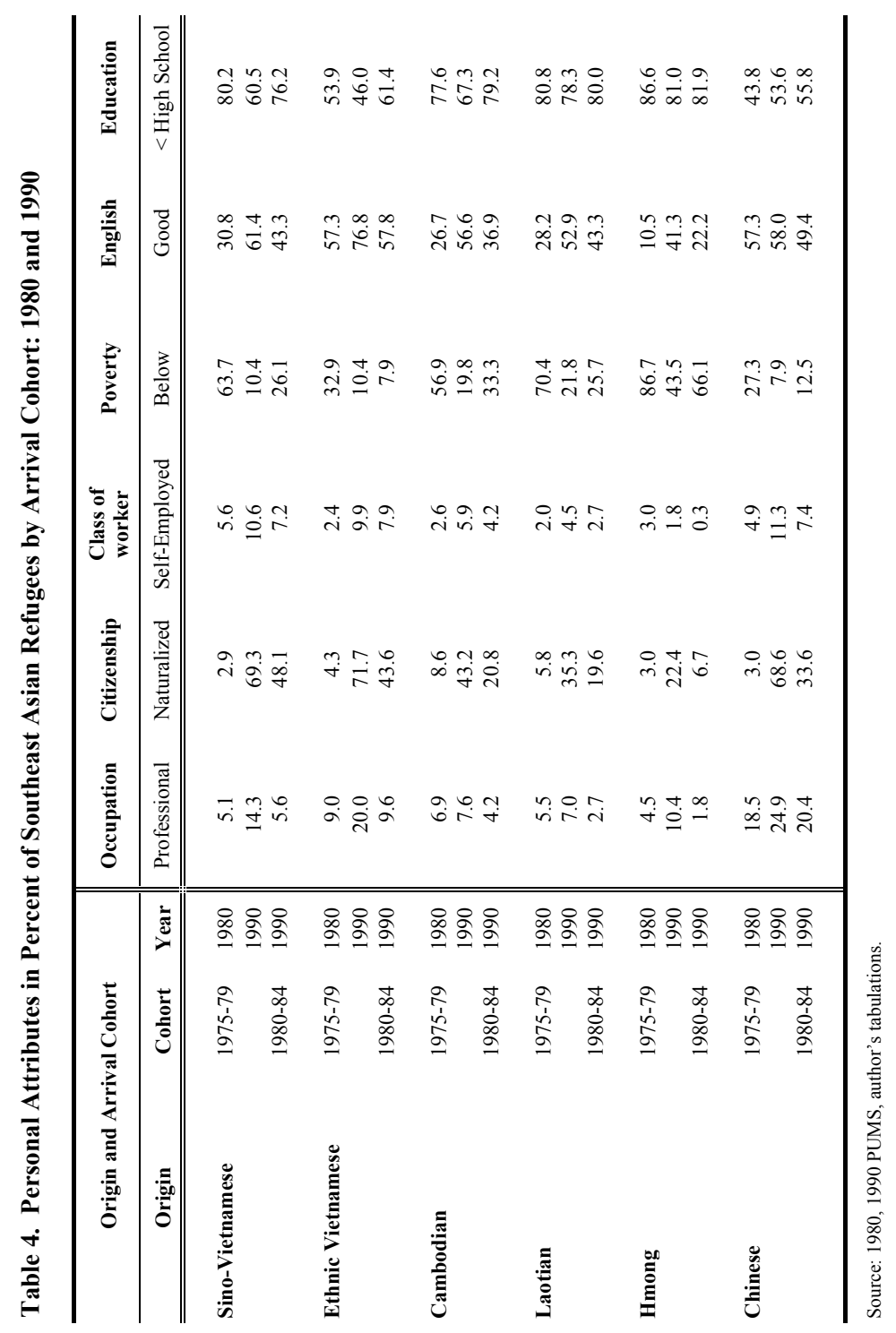


labour market involvement, indicating their difficulty in finding employment (Portes and Rumbaut 1996). Given the diversity of education levels, it is not surprising that a similar relationship is found with respect to occupation and employment status. Groups such as the Chinese and Vietnamese, who have higher levels of education, tend to have a larger proportion engaged in professional occupations (24.9, 14.3, and 20.0 percent, respectively, among 1975-79 Chinese, Sino-Vietnamese and Ethnic-Vietnamesearrivals in 1990). Cambodians, Laotians, and Hmong all had lower levels of participation in professional occupations, even by 1990 (7.6, 7.0, and 10.4 percent, respectively). Not surprisingly, arrivals between 1980-84 had lower levels of participation in professional occupations in 1990 than those who arrived in the late 1970s.

Self-employment is another important indicator of socioeconomic status and adaptation. In general, immigrant minorities are more likely to be self-employed, being barred through discrimination, language, or other effects from participation in the paid-employment sector of the economy (Portes and Rumbuat 1996). Although the census definition of self-employment fails to distinguish between casual wageworkers and those with an established business, self-employment may still be seen as an indicator of economic self-reliance and as a potential means for upward mobility. In 1990, the rate of self-employment in the U.S. was approximately 7 percent (Portes and Rumbaut 1996). By 1990, approximately 10 percent of the Vietnameseand 11 percent of Chinese who arrived between 1975 and 1979 were self-employed.At 1.8 percent, the Hmong, who had arrived in the U.S. during the same five-year window and shared a similar age profile, had the lowest level of self-employment.

A good summary of the relative economic position of these groups is a measure of poverty, with wide variations across the groups not surprising given the differences in occupation, education and employment. Chinese arrivals were least likely to be below the poverty line, indicating both the level of human capital that they arrived with and the ability of the Chinese community to integrate new arrivals. Among the refugee groups, the Vietnamese were in the strongest economic position, with just 10 percent of the earliest arrivals below the poverty level by 1990. In contrast, nearly 44 percent of the Hmong who arrived at the same time were still below the poverty line as late as 1990 . Recent (1980-84) arrivals were also more likely to be below the poverty line in 1990, with recency of arrival and poor skills being obvious explanations.

Non-economic indicators of adjustment and their variation across refugee groups can also be evaluated. As measures of the ability to function and interact within the larger society, the ability to speak English becomes an important indicator of acculturation, with respondents asked to self-rank their English ability. For those arriving between 1975-79, English abilities improved so that by 1990, approximately 61 percent of Sino-Vietnameseand 77 percent of Ethnic Vietnamese could speak English 'well'. Cambodians and Laotians occupied a middle range, while the Hmong had the poorest abilities, with only 44 percent ranking their English abilities as 'well'. While fluent bilingualism escapes a large proportion of the refugee population, Chinese immigrant arrivals do not necessarily fare better than their refugee counterparts, showing far less improvement in English skills 
between 1980 ( 57.3 percent) and 1990 (58.0 percent). It is unlikely that this means that new arrivals are refusing to learn English. Rather, the relative institutional completeness of particular communities may slow their advancement, allowing recent arrivals to function within an environment that requires little adaptation by creating economic and social opportunities for newcomers not found outside the community. While beneficial, such institutional completeness may also ultimately delay interaction and assimilation with the larger host society.

Finally, citizenship offers an indirect measure of attachment to the host society. By definition, it is unlikely that refugees will be able or willing to return home, affecting their attitudes toward America along with their adaptation (Portes and Borocz 1989). By 1990, approximately 70 percent of pre-1980 Vietnamese arrivals were naturalized citizens, a proportion that exceeded naturalization among the Chinese (68.6 percent). Less than 50 percent of the Cambodian, Hmong and Laotian refugees who arrived in America during the same period were naturalized. Barriers of language and abilities may make them less aware and able to complete the steps in the citizenship process and preventing them from moving in this direction. For them, the goal of citizenship may be attained only over the much longer term.

Clearly, the above discussion reveals that improvement in one indicator does not necessarily translate into improvements in other indicators, even within the same group. For example, the percentage of Laotians arriving between 1980 and 1990 who were below the poverty line dropped from 70.4 percent to 21.8 percent, even as class of worker, educational attainment, and occupation changed little over the same interval. Although a comparator group, the percentageof Chinese who arrived between 1975-79 and indicated that they could speak English well changed only marginally (and insignificantly) between 1980 and 1990, most likely reflecting the presence of well-established Chinese communities. At the same time, the proportion in poverty decreased from 27.3 to 7.9 percent and the proportion engaged in professional occupations grew from 18.5 to 24.9 percent.

\section{Discussion and Conclusions}

Reflecting violence associated with national fragmentation, self-determination, and conflicts relating to race, elitism, religion, or the environment, the number of refugees worldwide is likely to increase in the coming years, with increasing pressure brought to bear upon the U.S. and other countries to resettle refugees. Once within the host country, however, there is an unspoken tendency to view refugees as part of the much larger foreign-born or immigrant population, both within the existing foreign-born literature as well as the lay-public. While they undoubtedly share similarities with this larger group, there are also key differences reflecting the nature of their relocation (forced) and their human capital (variable). Moreover, the common decision to disperse the refugee population upon arrival decreases the ability to interact with co-nationals given the typically small preexisting co-national populations. In contrast to those who immigrate for economic opportunities or family reunification, refugees are forced to relocate and are often 
the least successful,frequently entering the host country with a poor or variable set of skills relative to other legal immigrants. In fact, there is relatively little within the literature that addresses the differences and/or similarities in the assimilation and adaptation process between immigrants and refugees, despite a wealth of literature that looks at these groups individually.

Focusing upon five Southeast Asian refugee groups, this paper has considered their changing geography and set of skills over 1980, 1985 and 1990 through the lens of segmented assimilation. The analysis reveals considerable differences in the assimilation processes across refugee groups, even after controlling for 'compositional' or age and period of arrival effects, with the empirical evidence supporting the segmented assimilation process: the adaptation of refugees differs through spatial, economic, social and cultural dimensions. Importantly, the study also shows the role of ethnic differences in assimilation, with ethnically defined refugee groups (as opposed to origin defined groups) differing significantly with respect to human capital and other measures of adaptation, reinforcing earlier work by Desbarats (1986).

Analysis of the measures of incorporation and settlement geography points to a complex and unequal process that transforms 'refugees' into 'immigrants' and ultimately 'Americans'. Although Southeast Asians apparently start out in the U.S. on an equal footing by virtue of the fact that they are all classified as 'refugees', this is an inaccurate assessment that fails to account for differing departure, arrival, and post-arrival experiences. The endowed human capital or skills that these groups bring with them will also influence the adjustmentprocess, allowing the possibility of more rapid socioeconomic advancement among those with higher skills. Moreover, it is far from a lock-step improvement in all measures of assimilation for each group. Instead, the improvement of one indicator, such as English language ability, may not correspond to any real change in occupational or educational structure.

The process of assimilation into American society is something that is only partially dependent upon the abilities and experiences that refugees bring with them. The question, therefore, is what else is responsible for the observed variations? Clearly, broader issues contextualize opportunities and their relative success or failure within the host country, with government policies, public and private reception, labour market and ethnic communitiesdefining the most relevant concepts of reception, with a combination of these influencing their incorporation into the host society. The economic incorporation, for example, of arrivals signals the importance of the ethnic community in the reception and adjustment of refugees. If no community exists, refugees face the host labour market directly, presenting the opportunity for racism and discrimination that may slow or define the adaptation process in ways that cannot be immediately measured. Economic standing also points to the importance of duration of residence effects. Time takes on added significance for the refugee population, since refugee flows are often associated with a declining socioeconomic background, meaning that the fate of later arrivals depends importantly on the community created by co-nationals, cushioning their arrival and adjustment. However, relative institutional completeness can also be a disadvantage, delaying adjustmentinto the host society. 
In recent decades, government policies have also played a key role in the admittance of refugees to the U.S., with public assistance available to refugees that is not available to other, legal immigrants. But, the availability of public aid may interact with other individual characteristics that potentially lead to different outcomes. Moreover, increasing anti-immigrant sentiments within American society, witnessed by Proposition 187 in California and welfare reform in 1996, may work to slow the adaptation of current and future refugees by withdrawing access to state or federal programs and monies. Instead, groups may be forced to

look inward to their own communities to replace these resources, placing better-off communities such as the Vietnamese at a relative advantage compared to poorer refugee groups who lack the social, cultural, economic or political resources. Similarly, discrimination is undoubtedly important in the adaptation of refugee communities, leading to differential levels of success within the host country. The racialization of the foreign-born community within the U.S., such that prejudices are transferredto any and/or all immigrants of colour, may also limit the adaptation of some groups. While Chinese immigrants have the advantage of large and wellestablished communities that can provide new arrivals with support, newer, economically and politically weaker communities will face additional problems. As articulated by George Sanchez (1999), hostility toward immigrants has taken on a new meaning (and urgency) as immigrants are fitted to established white versus black racial patterns, making racism against Asians, or any other identifiable immigrant group, an extension of the dominant white-black racism. The use of a black and white lens to view immigrants tends to dull awareness of other racial tensions and identities, and it is made more problematic by its denial of alternate realities.

\section{Acknowledgements:}

This research was funded by a grant from the Social Science Research Council, International Migration Program. This research was conducted while the author held a SSRC International Migration Program Fellowship at the University of Illinois, Urbana-Champaign. He gratefully acknowledges their support.

\section{References:}

Allen, J.P. and E. Turner. 1996. "Spatial patterns of immigrant assimilation," The Professional Geographer 48:140-155.

Aycan, Z. and J.W. Berry. 1996. "Impact of employment-related experiences on immigrants' psychological well-being and adaptation to Canada," Canadian Journal of Behavioural Science 28(3): 240-251.

Baker, R.P. and D.S. North. 1984. The 1975 Refugees: Their First Five Years in America. Washington, DC: New TransCentury Foundation

Bean, F.D. and M. Tienda. 1987. The Hispanic Population of the United States. New York: Russell Sage. 
Refugees into Immigrants: Assessing the Adjustment of Southeast Asian Refugees in the U.S., 1975-1990

Borjas, G. J. 1985. "Assimilation, changes in cohort quality, and the earnings of immigrants," Journal of Labor Economics 3: 463-489.

Borjas, G. J. and B. Bratsberg. 1996. "Who leaves? The outmigration of the foreign-born," The Review of Economics and Statistics 165-176.

Chataway, C. J. and J. W. Berry. 1989. “Acculturation experiences, appraisal, coping, and adaptation: A comparison of Hong Kong Chinese, French, and English students in Canada," Canadian Journal of Behavioural Science 21(3): 295-309.

Clark, W. A. V. 1998. The California Cauldron. New York: Guilford.

Desbarats, J. 1985. "Indochinese resettlement in the United States," Annals of the Association of American Geographers 75(4): 405-427.

Desbarats, J. 1986. "Ethnic differences in adaptation: Sino-Vietnamese refugees in the United States," International Migration Review 20: 405-427.

Frey, W. 1996. "Immigrant and native migrant magnets," American Demographics 18(11): 37-53.

Goldman, G. 1998. "The measurement of acculturation," Canadian Studies in Population 25(2): 115-144.

Gordon, M. 1964. Assimilation in American Life: The Role of Race, Religion and National Origins. New York: Oxford University Press.

Gordon, L. 1989. "National surveys of Southeast Asian refugees: Methods, findings, issues," in D.W. Haines (ed.) Refugees as Immigrants. Totawa, NJ: Rowman Littlefield, 24-39.

Haines, D.W. 1989. Refugees as Immigrants, Totawa, NJ: Rowman Littlefield.

Hirschman, C. 2001. "The educational enrollment of immigrant youth: A test of the segmented-assimilation hypothesis," Demography 38(3): 317-336.

Isajiw, W. 1999. Understanding Diversity: Ethnicity and Race in the Canadian Context. Toronto: Thompson Educational.

Isbister, J. 1996. The Immigration Debate: Remaking America. West Hartford, CT: Kumarian Press.

Massey, D. S. 1985. "Ethnic residential segregation: A theoretical and empirical review," Sociology and Social Research 69: 315-350. 
McHugh, K. E., I. N. Miyares and E. H. Skop. 1997. "The magnetism of Miami: Segmented paths in Cuban migration," Geographical Review, 87(4): 504-519.

Myers, D. and S. W. Lee. 1996. "Immigration cohorts and residential overcrowding in Southern California," Demography 33(1):51-65.

Newbold, K. B. 1999. "Evolutionary immigrant settlement systems: Concepts and evidence", in K. Pandit and S. Davies-Withers (eds.) Migration and Restructuring in the United States. Totawa, NJ: Rowman Littlefield, $250-270$.

Newbold, K. B. 2000. Immigrants, refugees and the non-permanent population: What are we missing when we discuss U.S. immigration? Paper presented at Annual Meetings of the Association of American Geographers, Pittsburgh, PA, March.

Park, R. E. 1928. Race and Culture. New York: The Free Press.

Portes, A. 1994. "Introduction: Immigration and its aftermath," International Migration Review 28(4): 632-639.

Portes, A. 1995. "Economic sociology and the sociology of immigration: A conceptual overview," in A. Portes (ed.) The Economic Sociology of Immigration. New York, NY: Russell Sage, 1-41.

Portes, A. and J. Borocz. 1989. "Contemporary immigration: Theoretical perspectives on its determinants and modes of incorporation," International Migration Review 23(3): 606-630.

Portes, A. and R. Rumbaut. 1996. Immigrant America: A Portrait Berkeley: University of California Press.

Portes, A. and M. Zhou. 1994. "Should immigrants assimilate?," The Public Interest 116: 18-33.

Sanchez, G. J. 1999. "Face the Nation: Race, Immigration, and the Rise of Nativism in Late-Twentieth Century America," in The Handbook of International Migration: The American Experience, ed C. Hirschman, P. Kasinitz and J. DeWind. New York: Russell Sage Foundation, 371-82.

Skop, E. M. 2001. "Race and place in the adaptation of Mariel exiles," International Migration Review 35(2): 449-471.

U.S. Bureau of the Census. 1983. Census of Population and Housing. 1980. Public Use Microdata Samples U.S. (Machine readable data files) / prepared by the Bureau of the Census. Washington, DC. 
Refugees into Immigrants: Assessing the Adjustment of Southeast Asian Refugees in the U.S., 1975-1990

U.S. Bureau of the Census. 1992. Census of Population and Housing. 1990. Public Use Microdata Samples U.S. (Machine readable data files) / prepared by the Bureau of the Census. Washington, DC.

U.S. Immigration and Naturalization Service. 1995. Statistical Yearbook of the Immigration and Naturalization Service, U.S. Government Printing Office: Washington, D.C..

Zlotnik, H. 1996. "Policies and migration trends in the North American system," in A.B. Simmons (ed.) International Migration, Refugee Flows, and Human Rights in North America. New York: Center for Migration Studies, 81-103.

Received February 2001; Revised October 2001 